\title{
Atividade antifúngica e possível mecanismo de ação do óleo essencial de folhas de Ocimum gratissimum (Linn.) sobre espécies de Candida
}

OLIVEIRA, L.B.S. ${ }^{*}$; BATISTA, A.H.M.1; FERNANDES, F.C.'; SALES, G.W.P.1; NOGUEIRA, N.A.P. ${ }^{1}$

'Universidade Federal do Ceará, Faculdade de Farmácia, Odontologia e Enfermagem, Rua Capitão Francisco Pedro, 1210, Rodolfo Teófilo, Fortaleza-CE, 60430-370. *Autor para correspondência: siebra.Iuciana@gmail.com

\begin{abstract}
RESUMO: A espécie Ocimum gratissimum (Linn.), popularmente conhecida como alfavacacravo, é muito utilizada na medicina popular. A planta apresenta inúmeros compostos, sendo o eugenol o constituinte majoritário do seu óleo essencial e o provável responsável pela sua atividade antimicrobiana. $\mathrm{O}$ objetivo deste estudo foi determinar o potencial antifúngico e o possível mecanismo de ação do óleo essencial extraído das folhas de O. gratissimum L. (OEOg) sobre cepas-padrão de Candida. Para avaliação da atividade antimicrobiana foi determinada a Concentração Inibitória Mínima (CIM), o efeito do tempo de exposição, o efeito modulador na atividade de antifúngicos (ATF) de uso clínico e a ação do OEOg nas fases de crescimento exponencial e estacionário de leveduras do gênero Candida. O mecanismo de ação do OEOg foi verificado por captação do cristal violeta e avaliação da morfologia microbiana pela técnica de microcultivo. Também foi avaliada a toxicidade do OEOg sobre hemácias humanas. O OEOg apresentou boa atividade antifúngica sobre cepas de Candida, sendo capaz de reduzir a taxa de crescimento das cepas de Candida a partir de quatro horas de exposição, além de ter modulado positivamente a atividade do cetoconazol para $C$. tropicalis ATCC 13803 e reduzir o número de células viáveis em todas as fases de crescimento microbiano. O OEOg foi capaz de promover o aumento discreto da captação do cristal violeta e provocou alterações na micromorfologia das células de Candida spp., sugerindo que seu alvo de ação seja o envoltório celular. Observou-se baixa toxicidade do OEOg sobre hemácias humanas. Os resultados encontrados mostraram que o OEOg possui boa atividade sobre o gênero Candida, com mecanismo de ação mediado possivelmente pela ocorrência de danos no envoltório celular, além de ter sido observada baixa toxicidade, indicando do OEOg é promissor no desenvolvimento e elaboração de um novo fármaco com potencial atividade para o tratamento de doenças fúngicas.
\end{abstract}

Palavras-chave: Ocimum, óleos essenciais, atividade antimicrobiana, farmacologia.

\begin{abstract}
Antifungal activity and potential action mechanisms of essential oil of Ocimum gratissimum (Linn.) leaves against Candida species. Ocimum gratissimum (Linn.) is a medicinal plant popularly known as "wild basil" widely used in traditional medicine. The plant has numerous compounds, and eugenol is the major constituent of its essential oil and likely responsible for its antimicrobial activity. The aim of this study was to determine the antifungal activity and the potential mechanism of action of the essential oil extracted from the leaves of $O$. gratissimum L. (OEOg) against standard strains of Candida. The following experiments were performed: determination of Minimum Inhibitory Concentration (MIC), determination of the effect of exposure time to OEOg; evaluation of the modulating effect of OEOg in antifungal (ATF) activity for clinical use; determination of the effects of the OEOg on different growth phases of Candida spp; determination of crystal violet (CV) uptake and the microculture of yeast technique. OEOg showed good antifungal activity against Candida, being able to reduce microbial growth during 24 hours of contact and also the number of viable cells at all stages of growth. OE positively modulates the activity of ketoconazole for C. tropicalis ATCC 13803. Increased uptake of CV and also the inhibition of Candidavirulence factors were also observed, which indicates the occurrence of damage in the cell envelope. These findings, coupled with the low toxicity of OEOg on human erythrocytes, indicate that "wild basil" is a promising plant for the development of a new drug with a potential activity to treat fungal diseases.
\end{abstract}

Key words: Ocimum, essential oils, antimicrobial activity, pharmacology. 


\section{INTRODUÇÃO}

O uso de plantas no tratamento e na cura de enfermidades é tão antigo quanto a espécie humana (Maciel et al. 2002). Nas últimas décadas, é notável a intensificação das pesquisas pela busca de compostos farmacologicamente ativos, visando uma forma terapêutica mais segura e acessível à população (Cechinel \& Yunes, 1998; Noldin, 2005).

Estudos de Matos (1998) documentam informações farmacológicas que justificam o uso popular de muitas espécies de plantas medicinais do nordeste brasileiro, entre elas encontra-se o Ocimum gratissimum Linn.

As folhas e ramos de $O$. gratissimum Linn são aromáticos e usados nas práticas de medicina caseira como estimulante, carminativa, diurética, contra tosse e, na forma de banhos, contra gripe em crianças. É excelente condimento em culinária (Matos, 2007).

Pesquisas sobre a atividade antimicrobiana de extratos de plantas, óleos essenciais e seus componentes têm-se centralizado no campo da medicina e terapêutica. Interesse justificado pelo aumento da resistência aos antimicrobianos sintéticos comerciais por patógenos associados a doenças infecciosas (Reichling et al. 2009).

Nas últimas décadas, houve um aumento no número de infecções fúngicas, especialmente em pacientes imuno-comprometidos ou em tratamento prolongado com antibióticos. Candida albicans é o agente causador da maioria das candidíases, mas outras espécies emergentes de Candida, incluindo C. glabrata e C. krusei, estão sendo responsáveis pela ocorrência de muitas infecções nosocomiais (Ahmad et al. 2011).

A ocorrência de casos de resistência dessa levedura a antifúngicos vem fazendo com que o gênero Candida seja objeto cada vez mais frequente de estudos relacionados à atividade antimicrobiana (Ahmad et al. 2010, Duarte et al. 2005). Assim, a pesquisa de novas substâncias capazes de combater infecções por Candida, ou mesmo melhorar a ação dos antifúngicos comumente usados na clínica, pode ser um caminho promissor a ser trilhado na luta contra a resistência e na redução das limitações do tratamento convencional, como efeitos adversos e a alta toxicidade (Zuzarte et al. 2012).

Dessa forma, o objetivo deste trabalho foi avaliar a atividade antifúngica e sugerir um possível mecanismo de ação do óleo essencial extraído das folhas de $O$. gratissimum L. (OEOg) sobre cepaspadrão de Candida.

\section{MATERIAL E MÉTODO}

\section{Material botânico}

As folhas frescas da espécie Ocimum gratissimum L. (alfavaca-cravo) foram coletadas no Horto de Plantas Medicinais Prof. Francisco José de Abreu Matos da Universidade Federal do Ceará (UFC) em Novembro de 2013 às 12 horas. A identificação botânica da espécie foi realizada no Departamento de Biologia da UFC, e sua exsicata encontra-se depositada no Herbário Prisco Bezerra, sob o número 52735.

\section{Extração e análise do OEOg}

O OEOg foi obtido por destilação por arraste a vapor em aparelho tipo Clevenger e a análise dos constituintes químicos foi realizada no Parque de Desenvolvimento Tecnológico do Ceará (PADETEC - UFC), em cromatógrafo gasoso acoplado à espectrometria de massa (CG-EM) (Matasyoh et al. 2007). Tween 80 a $1 \%$ foi utilizado como solvente do OEOg. A identificação dos constituintes do OEOg foi efetuada através da determinação dos índices de Kovats experimentais. O rendimento da extração foi de $0,36 \%(p / v)$.

\section{Leveduras estudadas}

Foram utilizadas quatro cepas-padrão de Candida: Candida albicans ATCC 10231, C. albicans ATCC 64124, C. parapsilosis ATCC 90018 e C. tropicalis ATCC 13803.

\section{OEOg \\ Avaliação da atividade antifúngica do}

A atividade antifúngica do OEOg foi avaliada pela determinação de sua Concentração Inibitória Mínima (CIM), do efeito do tempo de exposição e da ação do OEOg nas fases de crescimento exponencial e estacionário de leveduras do gênero Candida

A determinação da CIM foi realizada pelo método de microdiluição em caldo de cultura (CLSI, 2008), modificado. Culturas microbianas $\left(10^{4} \mathrm{UFC} / \mathrm{mL}\right)(80 \mu \mathrm{L})$, Caldo Sabouraud Dextrose $2 \%$ (CSD) $(100 \mu \mathrm{L})$ e diferentes concentrações de óleo essencial $(5 \mathrm{mg} / \mathrm{mL}$ a $0,0048 \mathrm{mg} / \mathrm{mL})(20 \mu \mathrm{L}$ ) foram adicionados aos poços de microplaca de 96 poços. As microplacas foram incubadas a 35 ${ }^{\circ} \mathrm{C}$ e após por $24 \mathrm{~h}$ foi realizada a inspeção visual do crescimento microbiano. A CIM foi considerada a menor concentração de OEOg capaz de inibir completamente o crescimento microbiano, mediante inspeção a olho nu. Os experimentos foram realizados em triplicata e os resultados expressos $\mathrm{em} \mathrm{mg} / \mathrm{mL}$. Agentes antifúngicos (cetoconazol, miconazol e nistatina) e solução aquosa de Tween

Rev. Bras. PI. Med., Campinas, v.18, n.2, p.511-523, 2016. 
80 a $1 \%$ estéril (diluente do OEOg) foram utilizados como controles dos experimentos.

Curvas de crescimento das cepas-padrão de Candida foram determinadas para que pudessem ser obtidas culturas microbianas nas fases de crescimento exponencial e estacionário. Para isso, o crescimento microbiano foi acompanhado pela contagem de colônias em meio sólido após 2, 4, $6,8,10,12,24,28,32$ e 48 h (Sales, 2014). Para determinar o efeito do tempo de exposição ao OEOg sobre a viabilidade celular de cepas de Candida foi seguida a metodologia descrita por Matasyoh et al. (2007), com algumas modificações. Alíquotas de 20 $\mu \mathrm{L}$ de OEOg, em CIM, foram adicionadas a poços de microplacas de 96 poços contendo $100 \mu \mathrm{L}$ de CSD e $80 \mu \mathrm{L}$ de uma suspensão microbiana $\left(10^{4}\right.$ UFC $/ \mathrm{mL}$ ). As microplacas foram incubadas a $35^{\circ} \mathrm{C}$ e após em intervalos de tempo predeterminados $(0,4,8,12$ e 24 horas), alíquotas de $10 \mu \mathrm{L}$ foram semeadas em ágar Plate-Count pela técnica da microgota (Romeiro, 2001). A contagem das colônias foi realizada após 24 horas de incubação a 35 ${ }^{\circ} \mathrm{C}$. Tween $801 \%$ foi utilizado como controle, os experimentos foram realizados em triplicata e os resultados expressos em UFC/mL.

$\mathrm{Na}$ avaliação do efeito do OEOg sobre cepas de Candida spp., nas diferentes fases de crescimento, foram utilizadas suspensões microbianas contendo aproximadamente $10^{4} \mathrm{UFC/}$ $\mathrm{mL}$. No inicio do período de incubação $(T=0)$, nas primeiras horas da fase exponencial de crescimento (4 e 8 horas) e após 24 horas (fase estacionária) de incubação a $35^{\circ} \mathrm{C}$ foram adicionados $20 \mu \mathrm{L}$ de OEOg aos poços da microplaca contendo suspensões microbianas, para obtenção de concentrações finais iguais a 1 e $2 \times \mathrm{CIM}$, previamente determinada. A contagem das células viáveis foi determinada após 4 e 24 horas da adição de OEOg. Os experimentos foram realizados em triplicata e os resultados expressos em UFC/mL (Muroi \& Kubo, 1996).

\section{Estudo do efeito modulador do OEOg na atividade de antifúngicos de uso clínico \\ $O$ efeito modulador do OEOg na atividade} de antifúngicos (ATF) de uso clínico foi avaliada pelo Método de Checkerboard, como descrito por Sales (2014). Aos poços de microplacas foram adicionadas alíquotas de $80 \mu \mathrm{L}$ de culturas microbianas $\left(10^{4}\right.$ UFC/mL), $80 \mu \mathrm{L}$ de CSD, $20 \mu \mathrm{L}$ do OEOg e $20 \mu \mathrm{L}$ dos ATF (nistatina, cetoconazol, miconazol). Foram utilizadas diferentes combinações OEOg+ATF, contendo concentrações finais iguais a 1/2, 1/4, 1/8, e $1 / 16$ x CIM de OEOg e de ATF. As microplacas foram incubadas durante 24 horas a $35^{\circ} \mathrm{C}$ e após esse período foi realizada a inspeção visual do crescimento microbiano. Os ensaios foram realizados em duplicata e os resultados obtidos foram avaliados quanto a modulação do OEOg na atividade antimicrobiana dos ATF testados. Para isso foram calculadas as concentrações inibitórias fracionadas (CIF) do OEOg e dos ATF e o índice da concentração inibitória fracionada (ICIF). As interações foram consideradas sinérgicas para ICIF $\leq 0,5$, aditivas ou indiferentes para ICIF $>0,5 \mathrm{e}<$ 1,0, e antagonistas para ICIF $\geq 1,0$ (EUCAST, 2003).

\section{do OEOg \\ Estudo preliminar do mecanismo de ação}

Aalteração na permeabilidade da membrana foi detectada pelo ensaio do cristal violeta conforme descrito por Devi et al. (2010). Para controles de experimento foram utilizados EDTA e culturas de Candida spp. em CSD não tratadas e tratadas com a nistatina. $\mathrm{O}$ valor de $\mathrm{DO}_{570 \mathrm{~nm}}$ da solução de cristal violeta $(10 \mu \mathrm{g} / \mathrm{mL}$ em PBS) foi considerado como $100 \%$ de absorção. Para o cálculo da captação do cristal foi usada a seguinte fórmula: DO da amostra/DO da solução de cristal violeta x 100. Os experimentos foram realizados em triplicata e os resultados expressos em \% de captação de CV.

Para observação de alterações na morfologia da levedura do gênero Candida foi empregada a técnica do microcultivo para leveduras utilizando o meio sólido ágar-fubá em câmara úmida (Castro, 2010). Alíquotas de $3 \mathrm{~mL}$ de ágar fubá, contendo 1x e 2x CIM de OEOg foram depositadas em lâminas estéreis apoiadas sobre um suporte contido em placa de Petri. Após solidificação do meio, inóculos das culturas de Candida spp. foram semeados, com auxílio de uma agulha esteril, em duas estrias paralelas. Em seguida, as lâminas foram cobertas com lamínulas de vidro estéreis e para evitar o ressecamento do meio, as lâminas foram mantidas em câmara úmida. Após 24, 48 e $72 \mathrm{~h}$ de incubação, as preparações foram examinadas em microscópio óptico no aumento de 40X para observação de ocorrência de alterações de estruturas características das leveduras.

\section{Estudo da citotoxicidade do OEOg}

O ensaio hemolítico foi conduzido como descrito por Harris \& Phoenix (1997). Alíquotas de $180 \mu \mathrm{L}$ da suspensão de eritrócitos humanos a $1 \%$ foram incubadas com $20 \mu \mathrm{L}$ do OEOg nas concentrações de $5 \mathrm{mg} / \mathrm{mL}$ a $0,04 \mathrm{mg} / \mathrm{mL}$. Após os 60 minutos de incubação a $35^{\circ} \mathrm{C}$, as amostras foram centrifugadas $2000 \mathrm{x}$ g por 5 minutos a $4{ }^{\circ} \mathrm{C}$ e o sobrenadante coletado para leitura da $\mathrm{DO}_{550 \mathrm{~nm}}$ da hemoglobina livre, em leitor ELISA (Bio-Tek). Hemácias integras tratadas com Triton X-100 0,1 $\%(\mathrm{v} / \mathrm{v})(100 \%$ de hemólise) e hemácias integras tratadas com tampão (PBS) (não hemólise) foram usadas como controles de experimento. Experimentos foram realizados em triplicata $\mathrm{e}$

Rev. Bras. PI. Med., Campinas, v.18, n.2, p.511-523, 2016. 
os níveis de hemólise foram determinados em porcentagem em relação ao controle de hemólise (Triton X-100 0,1\%).

\section{Análise estatística}

A análise estatística foi realizada com o auxílio do programa GraphPad Prism 5.0. Os resultados foram expressos como Média \pm Erro Padrão da Média (EPM) de três experimentos. Para a verificação das diferenças estatísticas entre os grupos foi realizada análise de variância (Anova) e pós-testes de Dunnet ou Bonferroni. As diferenças foram consideradas significantes quando $p<0,05$

\section{Comitê de ética}

O estudo foi aprovado pelo Comitê de Ética em Pesquisa da Universidade Federal do Ceará, com número do parecer: 751.168.

\section{RESULTADOS}

\section{Avaliação da composição química do OEOg} $\mathrm{Na}$ análise por cromatografia gasosa, evidenciou-se que o OEOg empregado nesse experimento contém como componentes majoritários Eugenol $(51,84 \%)$ e 1,8-Cineol $(23,81 \%)$, além de outros seis componentes minoritários (Tabela 1).

TABELA 1. Constituintes químicos do OEOg

\begin{tabular}{lccc}
\hline Constituinte Químico & I.K & I.K $_{E}$ & $\%$ Total \\
\hline $\boldsymbol{\beta}$-Pineno & 965 & 964 & 1,60 \\
1,8-Cineol & 1004 & 1013 & 23,81 \\
$\boldsymbol{\beta}$-Ocimeno & 1021 & 1016 & 3,18 \\
Eugenol & 1364 & 1358 & 51,84 \\
$\boldsymbol{\beta}$-Cariofileno & 1418 & 1418 & 5,79 \\
Germacreno D & 1480 & 1481 & 2,19 \\
$\boldsymbol{\beta}$-Selenine & 1482 & 1489 & 8,88 \\
$\boldsymbol{\alpha}-S e l e n i n e$ & 1498 & 1496 & 2,71 \\
\hline Total Identificado & & & $100 \%$ \\
\hline
\end{tabular}

*I.K: Índice de Kovats da literatura. I.K $\mathrm{K}_{\mathrm{E}}$ Índice de Kovats experimental.

\section{OEOg \\ Avaliação da atividade antifúngica do}

Na Tabela 2 estão os resultados de CIM do OEOg para as cepas de Candida testadas.

A Figura 1 apresenta a influência do tempo de exposição ao OEOg na viabilidade das cepas de Candida. A exposição a CIM de OEOg, após $24 \mathrm{~h}$, reduziu o crescimento microbiano em $75,5 \%, 70,1 \%, 72 \%$ e $80,8 \%$ quando comparado ao crescimento das culturas sem tratamento, para as cepas de C. albicans ATCC 10231, C. albicans ATCC 64124, C. parapsilosis ATCC 90018 e C. tropicalis ATCC 13803, respectivamente. O OEOg inibiu o crescimento de todas as cepas testadas, a partir de $4 \mathrm{~h}$ de contato.

O OEOg foi capaz de reduzir o número de células quando adicionado às culturas no início do período de incubação ( $T=0 h)$, na fase de crescimento exponencial ( $T=4 \mathrm{~h}$ e $8 \mathrm{~h}$ ) e na fase estacionária (24h), sendo mais eficaz nas primeiras horas de contato (Figuras 2 e 3 ).

\section{Estudo do efeito modulador do OEOg na atividade de antifúngicos de uso clínico \\ A modulação do OEOg na atividade} antimicrobiana do Cetoconazol, do Miconazol e da Nistatina foi avaliada pelo método de Checkerboard (Tabelas 3 a 5). O OEOg modulou positivamente a ação do cetoconazol, em três das combinações testadas (ICIF entre 0,5 e 0,125 ) sobre a cepa Candida tropicalis ATCC 13803.

Estudo do mecanismo de ação do OEOg

A CIM de OEOg foi capaz de promover um aumento na captação do cristal violeta em $10,5 \%, 8.27 \%, 7.63 \%$ e $4.9 \%$ pelas cepas de $C$. albicans ATCC 10231 e C. albicans ATCC 64124, C. tropicalis ATCC 13803 e C. parapsilosis 90018 , respectivamente, quando comparado ao controle não tratado, indicando a ocorrência de alterações nos envoltórios celulares (Figura 4).

No ensaio da micromorfologia das cepas de Candida foi observada, com auxílio de microscópio óptico, a presença de estruturas características do

TABELA 2. CIM do OEOg e de antifúngicos sobre cepas-padrão de Candida.

\begin{tabular}{lcccc}
\hline Cepa & OEOg & CET & $\mathrm{MIC}$ & $\mathrm{NIS}$ \\
\hline & $\begin{array}{c}\mathrm{CIM}^{*} \\
(\mu \mathrm{g} / \mathrm{mL})\end{array}$ & $\begin{array}{c}\mathrm{CIM}^{*} \\
(\mu \mathrm{g} / \mathrm{mL})\end{array}$ & $\begin{array}{c}\mathrm{CIM}^{*} \\
(\mu \mathrm{g} / \mathrm{mL})\end{array}$ & $\begin{array}{c}\mathrm{CIM}^{*} \\
(\mu \mathrm{g} / \mathrm{mL})\end{array}$ \\
\hline C. albicans ATCC 10231 & 1250 & 8 & 4 & 8 \\
C. albicans ATCC 64124 & 625 & 8 & 8 & 8 \\
C. parapsilosis ATCC 90018 & 1250 & 0,0625 & 1 & 16 \\
C. tropicalis ATCC 13803 & 1250 & 4 & 4 & 16 \\
\hline
\end{tabular}

* Concentração inibitória minima de OEOg e do antifúngico. Controles de experimento: CET (Cetoconazol), MIC (Miconazol), NIS (Nistatina) e DMSO 1\% (sem atividade). Volume de OE aplicado em cada poço: $20 \mu \mathrm{L}$. Experimentos realizados em triplicata. 

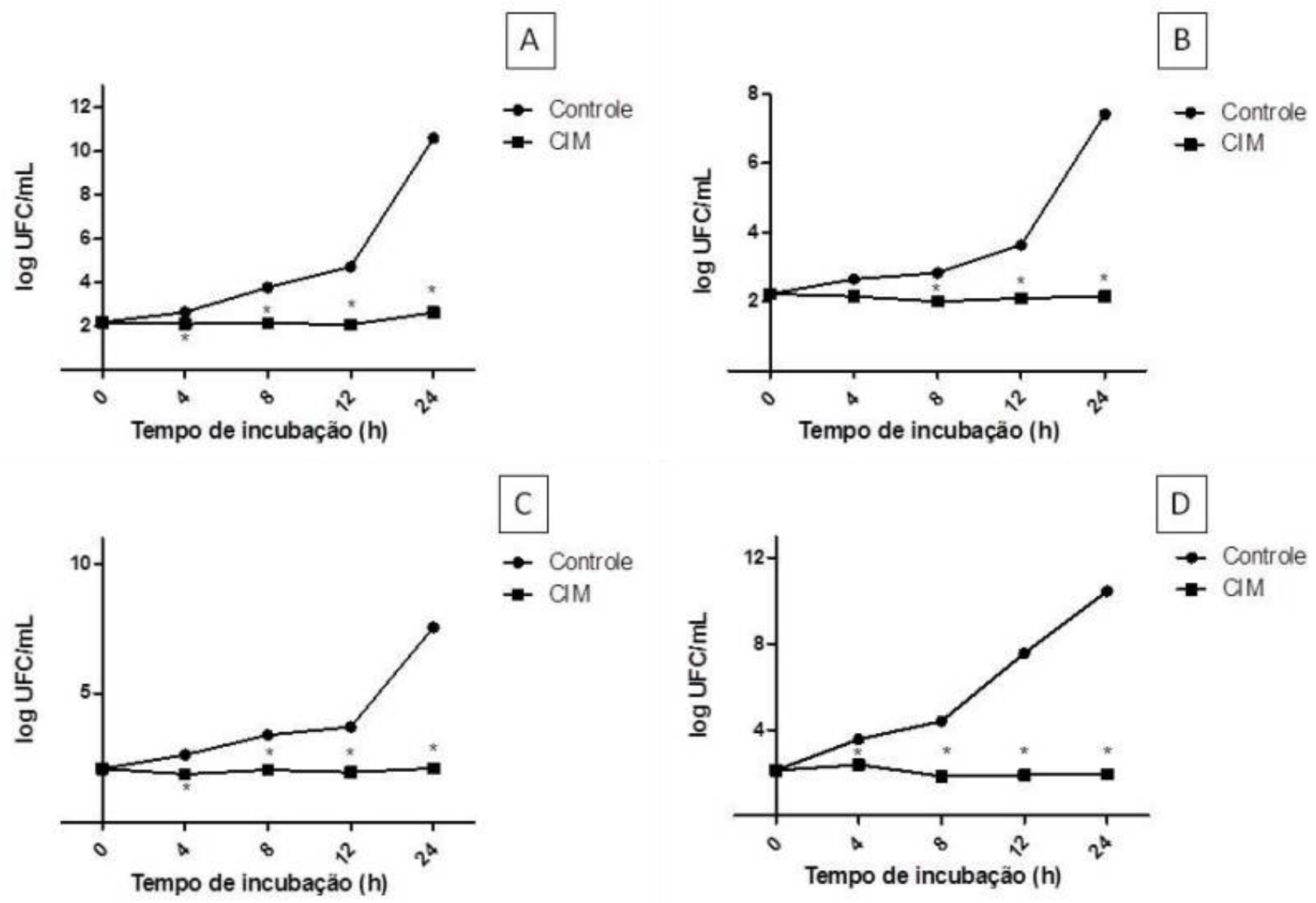

FIGURA 1. Efeito do tempo de exposição do OEOg na viabilidade de Candida spp.

A: C. albicans ATCC 10231; B: C. albicans ATCC 64124, C. parapsilosis ATCC 90018; C. tropicalis ATCC 13803. — CIM A, C, D: 1,25 mg/ $\mathrm{mL}$; CIM B: $0,625 \mathrm{mg} / \mathrm{mL}$; C Controle: sem tratamento. Os valores estão expressos pela média \pm EPM de três experimentos. A análise foi realizada por ANOVA, com pós-teste de Bonferroni e valor de ${ }^{*} p<0,05$ quando comparado ao controle. Os valores representam a média \pm EPM de três experimentos.

TABELA 3. Efeito modulador do OEOg na atividade antifúngica do Cetoconazol sobre cepas de Candida.

\begin{tabular}{|c|c|c|c|c|c|c|c|}
\hline \multirow[t]{2}{*}{ Micro-organismo } & \multicolumn{2}{|c|}{$\mathrm{CIM}_{\mathrm{OEOg}}$} & \multirow[t]{2}{*}{$\mathrm{CIF}_{\mathrm{OEOg}}$} & \multicolumn{2}{|l|}{$\mathrm{CIM}_{\mathrm{CET}}$} & \multirow[t]{2}{*}{$\mathrm{CIF}_{\mathrm{CET}}$} & \multirow[t]{2}{*}{ ICIF } \\
\hline & $\mathrm{l}$ & $A$ & & 1 & $A$ & & \\
\hline \multirow[b]{2}{*}{ C. albicans } & 1,25 & 0,625 & 0,5 & 32 & 16 & 0,5 & 1 \\
\hline & 1,25 & 0,625 & 0,5 & 32 & 8 & 0,25 & 0,75 \\
\hline \multirow[t]{2}{*}{ ATCC 10231} & 1,25 & 0,625 & 0,5 & 32 & 4 & 0,125 & 0,625 \\
\hline & 1,25 & 0,625 & 0,5 & 32 & 2 & 0,0625 & 0,5625 \\
\hline \multirow[b]{2}{*}{ C. albicans } & 0,625 & - & - & 4 & - & - & $>1$ \\
\hline & 0,625 & - & - & 4 & - & - & $>1$ \\
\hline \multirow{2}{*}{ ATCC 64124} & 0,625 & - & - & 4 & - & - & $>1$ \\
\hline & 0,625 & - & - & 4 & - & - & $>1$ \\
\hline \multirow[b]{2}{*}{ C. parapsilosis } & 1,25 & - & - & 0,0625 & - & - & $>1$ \\
\hline & 1,25 & - & - & 0,0625 & - & - & $>1$ \\
\hline \multirow[t]{2}{*}{ ATCC 90018} & 1,25 & - & - & 0,0625 & - & - & $>1$ \\
\hline & 1,25 & - & - & 0,0625 & - & - & $>1$ \\
\hline \multirow[b]{2}{*}{ C. tropicalis } & 1,25 & 0,625 & 0,5 & 4 & 2 & 0,5 & 1 \\
\hline & 1,25 & 0,3125 & 0,25 & 4 & 1 & 0,25 & 0,5 \\
\hline \multirow[t]{2}{*}{ ATCC 13803} & 1,25 & 0,156 & 0,125 & 4 & 0,5 & 0,125 & 0,250 \\
\hline & 1,25 & 0,078 & 0,0625 & 4 & 0,25 & 0,0625 & 0,125 \\
\hline
\end{tabular}

$\mathrm{CIM}_{\text {OEOG: }}$ : CIM do OEOg $(\mathrm{mg} / \mathrm{mL}) ; \mathrm{CIM}_{\mathrm{CET}}$ : CIM do CET ( $\left.\mu \mathrm{g} / \mathrm{mL}\right)$; I: OEOg ou CET isolados; A: associação OEOg-CET; CIF ${ }_{\text {OEOg: }}$ CIM do OEOg na associação/CIM do OEOg isolado; $\mathrm{CIF}_{\mathrm{CET}}$ : $\mathrm{CIM}$ do CET na associação/CIM do CET isolado. Índice $\mathrm{CIF}=\mathrm{CIF}_{\mathrm{OEOg}}+\mathrm{CIF}_{\mathrm{CET}}$. ICIF $\leq 0,5$ : sinergismo; ICIF > 0,5 e <1,0: aditivo ou indiferente; ICIF $\geq 1$ : antagonismo (EUCAST, 2003). 

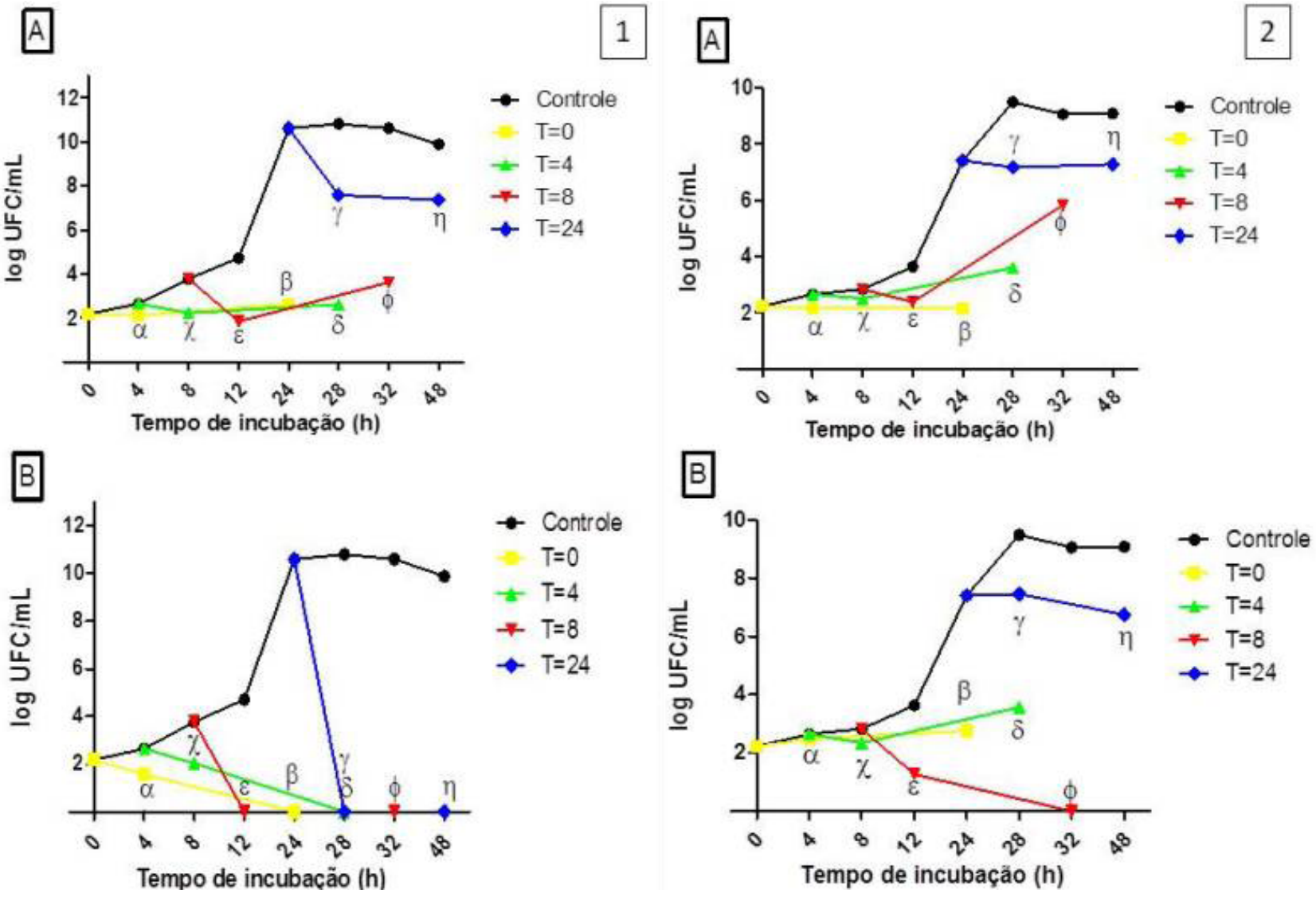

FIGURA 2. Efeito do OEOg sobre C. albicans ATCC 10231 e C. albicans ATCC 64124 nas fases de crescimento exponencial e estacionário.

O OEOg foi adicionado nos tempos 0h ( $\bullet), 4 \mathrm{~h}(\boldsymbol{\Delta}), 8 \mathrm{~h}(\boldsymbol{\nabla})$ e 24h (४) após o início da incubação. A contagem de células viáveis foi determinada após 4 e 24 horas da adição do OEOg. Controle $(\bullet)$ sem tratamento. (A): CIM; (B): 2 X CIM. A análise estatística foi realizada por ANOVA, com pós-teste de Bonferroni, com $\mathrm{p}<0,05$. 1: C. albicans ATCC 10231; B: C. albicans ATCC 64124.

$\alpha$ e $\beta=$ comparação entre $T=0$ e o grupo controle, após 4 e 24 horas da adição, respectivamente, no tempo 0h; $x$ e $\delta=$ comparação entre $\mathrm{T}=4$ e o grupo controle, após 4 e 24 horas da adição, respectivamente, no tempo $4 \mathrm{~h}$. $\varepsilon$ e $\varphi=$ comparação entre $\mathrm{T}=8$ e $o$ grupo controle, após 4 e 24 horas da adição, respectivamente, no tempo 8h; y e $\eta=$ comparação entre $T=24$ e o grupo controle, após 4 e 24 horas da adição, respectivamente, no tempo $24 \mathrm{~h}$.

TABELA 4. Efeito modulador do OEOg na atividade antifúngica do Miconazol sobre cepas de Candida.

\begin{tabular}{|c|c|c|c|c|c|c|c|}
\hline \multirow[t]{2}{*}{ Microorgansmo } & \multicolumn{2}{|c|}{$\mathrm{CIM}_{\mathrm{OEOO}}$} & \multirow[t]{2}{*}{$\mathrm{CIF}_{\mathrm{OEOg}}$} & \multicolumn{2}{|c|}{$\mathrm{CIM}_{\text {MIC }}$} & \multirow[t]{2}{*}{$\mathrm{ClF}_{\mathrm{MC}}$} & \multirow[t]{2}{*}{$\mathrm{ICIF}$} \\
\hline & 1 & A & & 1 & A & & \\
\hline \multirow[b]{2}{*}{ C. albicans } & 1,25 & - & - & 4 & - & - & $>1$ \\
\hline & 1,25 & - & - & 4 & - & - & $>1$ \\
\hline \multirow[t]{2}{*}{ ATCC 10231} & 1,25 & - & - & 4 & - & - & $>1$ \\
\hline & 1,25 & - & - & 4 & - & - & $>1$ \\
\hline \multirow[b]{2}{*}{ C. albicans } & 0,625 & - & - & 8 & - & - & $>1$ \\
\hline & 0,625 & - & - & 8 & - & - & $>1$ \\
\hline \multirow[t]{2}{*}{ ATCC 64124} & 0,625 & - & - & 8 & - & - & $>1$ \\
\hline & 0,625 & - & - & 8 & - & - & $>1$ \\
\hline \multirow[b]{2}{*}{ C. parapsilosis } & 1,25 & 0,625 & 0,5 & 2 & 1 & 0,5 & 1 \\
\hline & 1,25 & 0,3125 & 0,25 & 2 & 1 & 0,5 & 0,75 \\
\hline \multirow[t]{2}{*}{ ATCC 90018} & 1,25 & 0,156 & 0,125 & 2 & 1 & 0,5 & 0,625 \\
\hline & 1,25 & 0,078 & 0,0625 & 2 & 1 & 0,5 & 0,5625 \\
\hline \multirow[b]{2}{*}{ C. tropicalis } & 1,25 & - & - & 4 & - & - & $>1$ \\
\hline & 1,25 & - & - & 4 & - & - & $>1$ \\
\hline \multirow{2}{*}{ ATCC 13803} & 1,25 & - & - & 4 & - & - & $>1$ \\
\hline & 1,25 & - & - & 4 & - & - & $>1$ \\
\hline
\end{tabular}

$\mathrm{CIM}_{\text {OEоG }}$ : CIM do OEOg $(\mathrm{mg} / \mathrm{mL}) ; \mathrm{CIM}_{\text {MIC }}$ : CIM do MIC $(\mu \mathrm{g} / \mathrm{mL})$; I: OEOg ou MIC isolados; A: associação OEOg-MIC; CIF na associação/CIM do OEOg isolado; $\mathrm{CIF}_{\mathrm{MIC}}$ : $\mathrm{CIM}$ do MIC na associação/CIM do MIC isolado. Índice $\mathrm{CIF}=\mathrm{CIF}_{\mathrm{OEOg}}+\mathrm{ClF}_{\mathrm{MIC}}$. ICIF $\leq 0,5$ : sinergismo; ICIF > 0,5 e <1,0: aditivo ou indiferente; ICIF $\geq 1$ : antagonismo (EUCAST, 2003). 

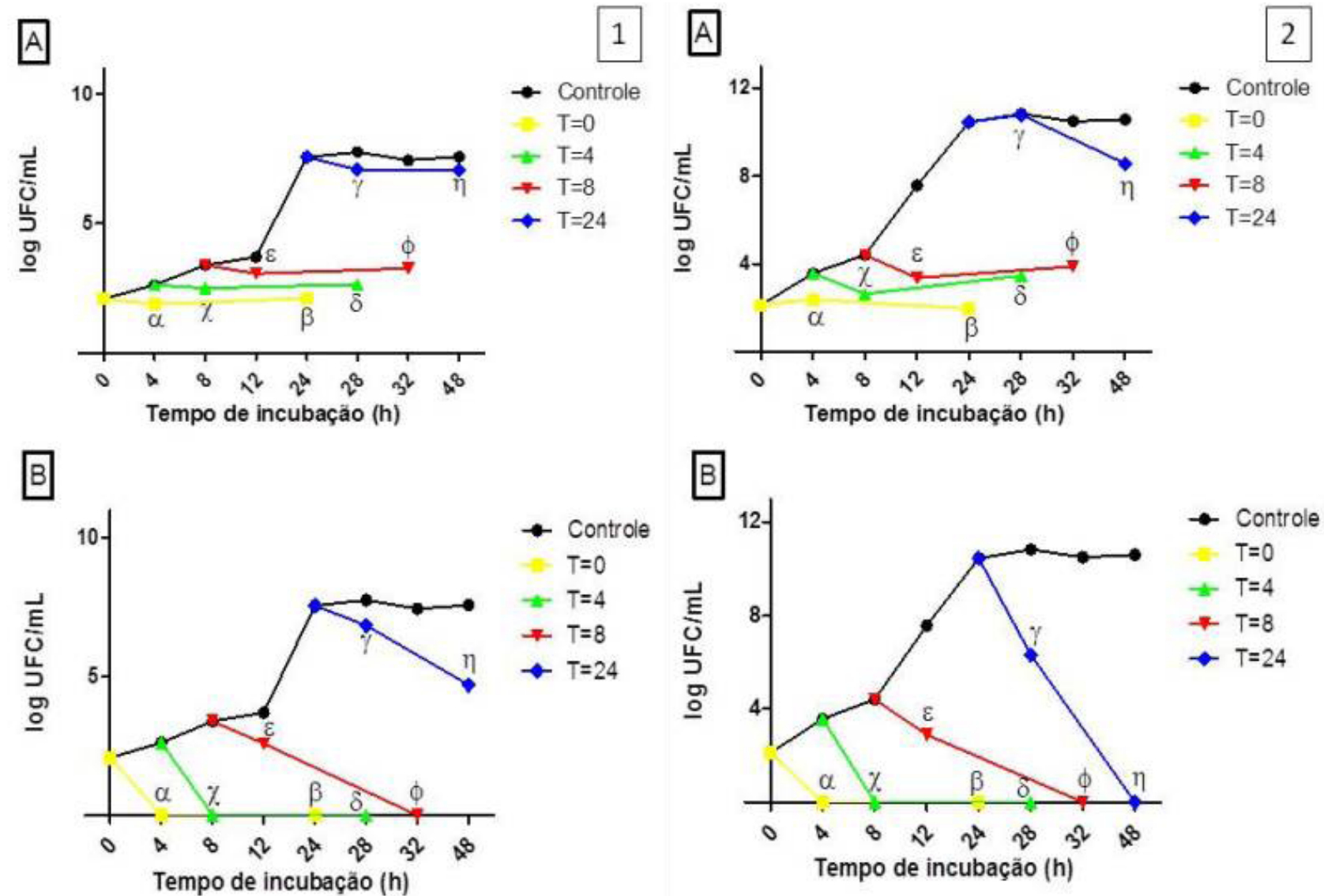

FIGURA 3. Efeito do OEOg sobre C. parapsilosis ATCC 90018 e C. tropicalis ATCC 13803 nas fases de crescimento exponencial e estacionário.

O OEOg foi adicionado nos tempos 0h ( $\bullet$ ), 4h $(\boldsymbol{\Delta})$, $8 \mathrm{~h}(\boldsymbol{\nabla})$ e $24 \mathrm{~h}(\bullet)$ após o início da incubação. A contagem de células viáveis foi determinada após 4 e 24 horas da adição do OEOg. Controle $(\bullet)$ sem tratamento. (A): CIM; (B): 2 X CIM. A análise estatística foi realizada por ANOVA, com pós-teste de Bonferroni, com $p<0,05.1$ : C. parapsilosis ATCC 90018; B: C. tropicalis ATCC 90018.

$\alpha$ e $\beta=$ comparação entre $T=0$ e o grupo controle, após 4 e 24 horas da adição, respectivamente, no tempo 0 ; $x$ e $\delta=$ comparação entre $\mathrm{T}=4$ e o grupo controle, após 4 e 24 horas da adição, respectivamente, no tempo $4 \mathrm{~h}$. $\varepsilon$ e $\varphi=$ comparação entre $T=8$ e $o$ grupo controle, após 4 e 24 horas da adição, respectivamente, no tempo 8h; y e $\eta=$ comparação entre T=24 e o grupo controle, após 4 e 24 horas da adição, respectivamente, no tempo $24 \mathrm{~h}$.

crescimento fúngico: pseudo-hifas, blastoconídios e clamidoconídios. Na presença do OEOg foram observados em sua maioria células isoladas, raras pseudo-hifas e blastoconídios. Na presença de nistatina foram visualizadas células isoladas e raros blastoconídios (Figuras de 5 a 8 ).

\section{Estudo da citotoxicidade do OEOg}

A taxa de hemólise determinada pelo CIM de OEOg foi de $14 \%$ e sua atividade hematotóxica apresentou-se concentraçãodependente (FIGURA 9).

CTween: Tween a $1 \%$; CSal: Salina; CSan:Controle da não hemólise (hemácias íntegras); CHemólise: Triton X-100 a 1\% (referência para 100\% de hemólise).

\section{DISCUSSÃO}

A caracterização química do $\mathrm{OEOg}$ identificou oito componentes, sendo o eugenol $(51,84 \%)$ e o 1,8 -cineol $(23,81 \%)$ os constituintes majoritários, resultados que estão de acordo com valores descritos na literatura (Sousa et al, 2004, Aguiar et al. 2015).

Óleos essenciais extraídos de várias espécies de Ocimum têm sido referidos como sendo ativos contra bactérias, assim como contra leveduras e fungos, devido a seus constituintes terpênicos (Pandey et al. 2014). Para o OEOg, a inibição de fungos pode ser justificada pela grande porcentagem de eugenol, composto fenólico antisséptico de ação já conhecida (Daferera et al., 2003; Costa et al, 2011).

O caráter lipofílico da sua cadeia de hidrocarbonetos e o carácter hidrófilo dos seus grupos funcionais são de grande importância 
TABELA 5. Efeito modulador do OEOg na atividade antifúngica da Nistatina sobre cepas de Candida.

\begin{tabular}{|c|c|c|c|c|c|c|c|}
\hline \multirow[t]{2}{*}{ Microorgansmo } & \multicolumn{2}{|c|}{$\mathrm{CIM}_{\mathrm{OEOg}}$} & \multirow[t]{2}{*}{$\mathrm{CIF}_{\mathrm{OEOg}}$} & \multicolumn{2}{|c|}{$\mathrm{CIM}_{\mathrm{NIS}}$} & \multirow[t]{2}{*}{$\mathrm{CIF}_{\mathrm{NIS}}$} & \multirow[t]{2}{*}{ ICIF } \\
\hline & 1 & A & & I & A & & \\
\hline \multirow[b]{2}{*}{ C. albicans } & 1,25 & 0,625 & 0,5 & 8 & 4 & 0,5 & 1 \\
\hline & 1,25 & 0,3125 & 0,25 & 8 & 4 & 0,5 & 0,75 \\
\hline \multirow[t]{2}{*}{ ATCC 10231} & 1,25 & 0,156 & 0,125 & 8 & 4 & 0,5 & 0,625 \\
\hline & 1,25 & 0,078 & 0,0625 & 8 & 4 & 0,5 & 0,5625 \\
\hline \multirow[b]{2}{*}{ C. albicans } & 0,625 & 0,3125 & 0,125 & 8 & 4 & 0,5 & 0,625 \\
\hline & 0,625 & 0,3125 & 0,125 & 8 & 4 & 0,5 & 0,625 \\
\hline \multirow[t]{2}{*}{ ATCC 64124} & 0,625 & 0,3125 & 0,125 & 8 & 4 & 0,5 & 0,625 \\
\hline & 0,625 & 0,3125 & 0,125 & 8 & 4 & 0,5 & 0,625 \\
\hline \multirow[b]{2}{*}{ C. parapsilosis } & 1,25 & 0,625 & 0,5 & 16 & 8 & 0,5 & 1 \\
\hline & 1,25 & 0,625 & 0,5 & 16 & 4 & 0,25 & 0,75 \\
\hline \multirow[t]{2}{*}{ ATCC 90018} & 1,25 & 0,625 & 0,5 & 16 & 2 & 0,125 & 0,625 \\
\hline & 1,25 & 0,625 & 0,5 & 16 & 1 & 0,0625 & 0,5625 \\
\hline \multirow[b]{2}{*}{ C. tropicalis } & 1,25 & 0,625 & 0,5 & 16 & 8 & 0,5 & 1 \\
\hline & 1,25 & 0,3125 & 0,25 & 16 & 8 & 0,5 & 0,75 \\
\hline \multirow[t]{2}{*}{ ATCC 13803} & 1,25 & 0,156 & 0,125 & 16 & 8 & 0,5 & 0,625 \\
\hline & 1,25 & 0,078 & 0,0625 & 16 & 8 & 0,5 & 0,5625 \\
\hline
\end{tabular}

$\mathrm{CIM}_{\text {OEOG }}:$ CIM do OEOg $(\mathrm{mg} / \mathrm{mL}) ; \mathrm{CIM}_{\text {MIC }}$ : CIM da NIS $(\mu \mathrm{g} / \mathrm{mL})$; I: OEOg ou NIS isolados; A: associação OEOg-NIS; CIF ${ }_{\text {OEOg }}$ : CIM do OEOg na associação/CIM do OEOg isolado; $\mathrm{CIF}_{\mathrm{NIS}}$ : $\mathrm{CIM}$ da NIS na associação/CIM da NIS isolada. Índice $\mathrm{CIF}=\mathrm{CIF}_{\mathrm{OEOg}}+\mathrm{CIF}_{\mathrm{NIS}}$. ICIF $\leq 0,5$ : sinergismo; ICIF > 0,5 e <1,0: aditivo ou indiferente; ICIF $\geq 1$ : antagonismo (EUCAST, 2003).
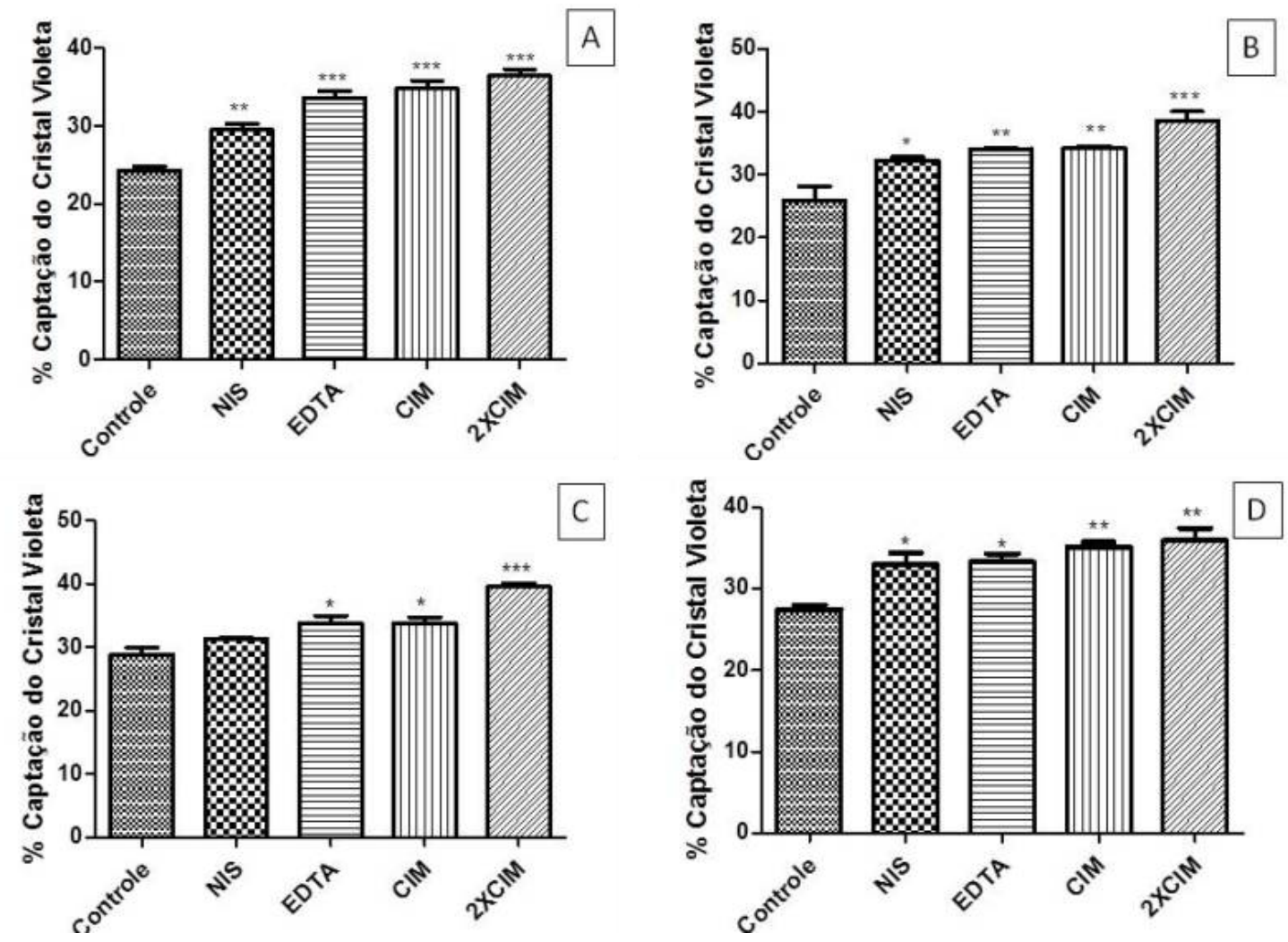

FIGURA 4. Captação do cristal violeta.

A: C. albicans ATCC 10231; B: C. albicans ATCC 64124, C. parapsilosis ATCC 90018; C. tropicalis ATCC 13803. Os valores representam a média \pm EPM de três ensaios. ${ }^{*} p<0,05$ comparado com o controle (sem tratamento). NIS (Nistatina $16 \mu g / m L$ ). EDTA - ácido etilenodiaminotetracético (controle positivo). CIM 

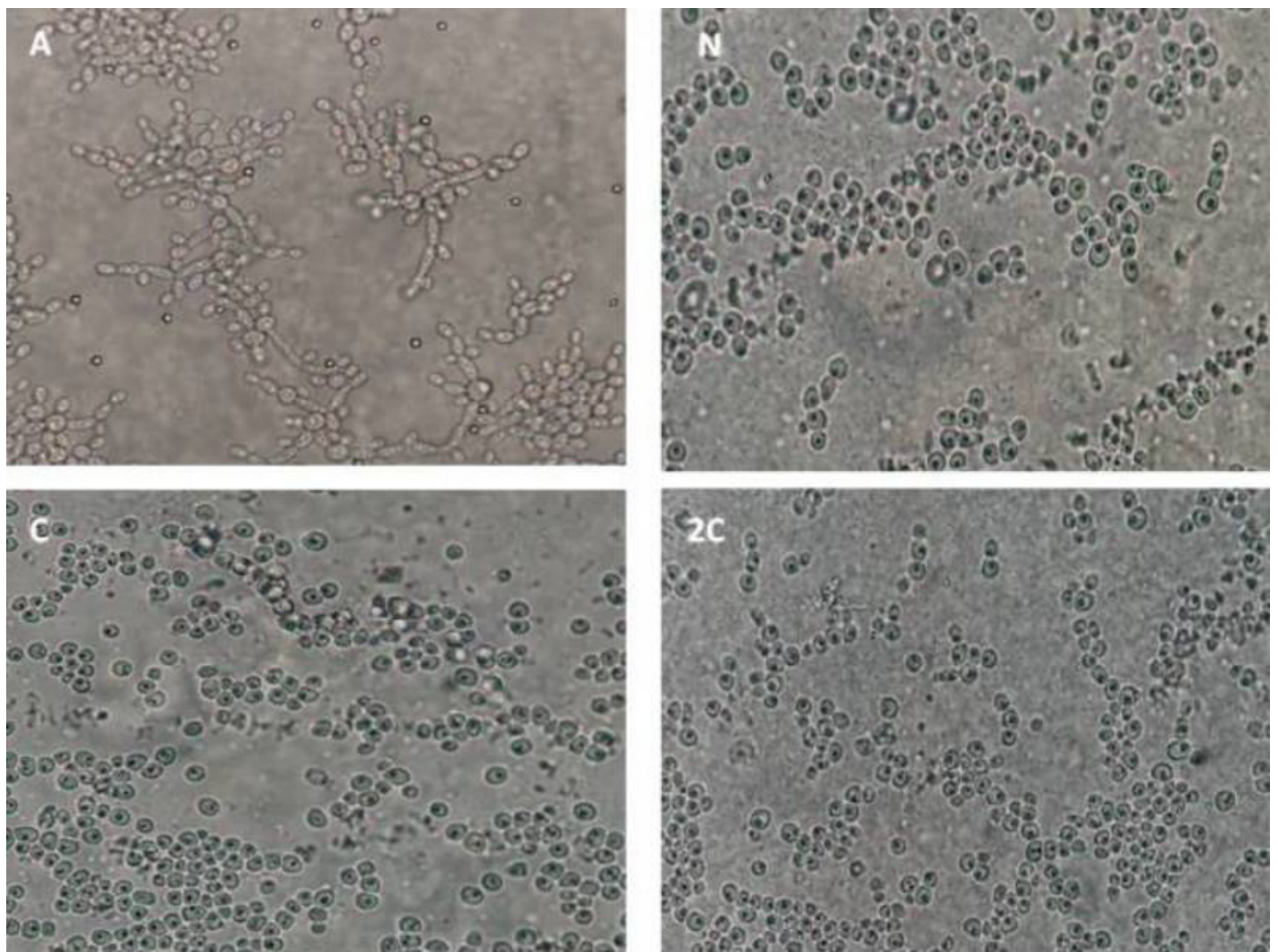

FIGURA 5. Micromorfologia de C. albicans ATCC 10231.

A - Controle sem tratamento; $\mathrm{N}$ - Cultura tratada com nistatina $(16 \mu \mathrm{g} / \mathrm{mL}) ; \mathrm{C}$ - Cultura tratada com CIM do OEOg $(1,25 \mathrm{mg} / \mathrm{mL}) .2 \mathrm{C}-$ Cultura tratada com 2xCIM do OEOg $(2,5 \mathrm{mg} / \mathrm{mL})$. Aumento de $40 \mathrm{X}$.
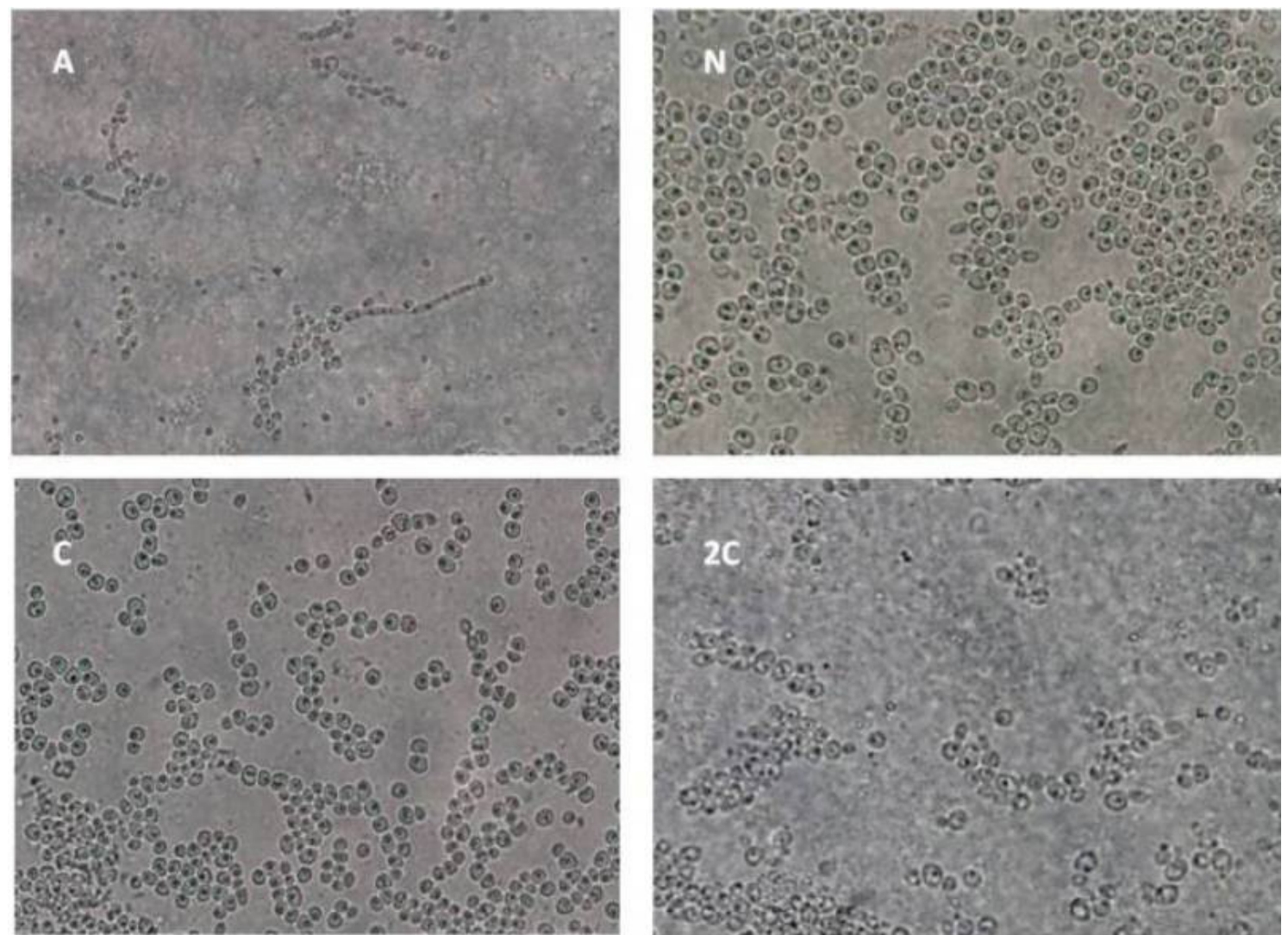

FIGURA 6. Micromorfologia de C. albicans ATCC 64124.

A - Controle sem tratamento; $\mathrm{N}$ - Cultura tratada com nistatina $(16 \mu \mathrm{g} / \mathrm{mL}) ; \mathrm{C}-$ Cultura tratada com CIM do OEOg $(0,625 \mathrm{mg} / \mathrm{mL})$. $2 \mathrm{C}-$ Cultura tratada com 2xCIM do OEOg $(2,5 \mathrm{mg} / \mathrm{mL})$. Aumento de $40 \mathrm{X}$. 

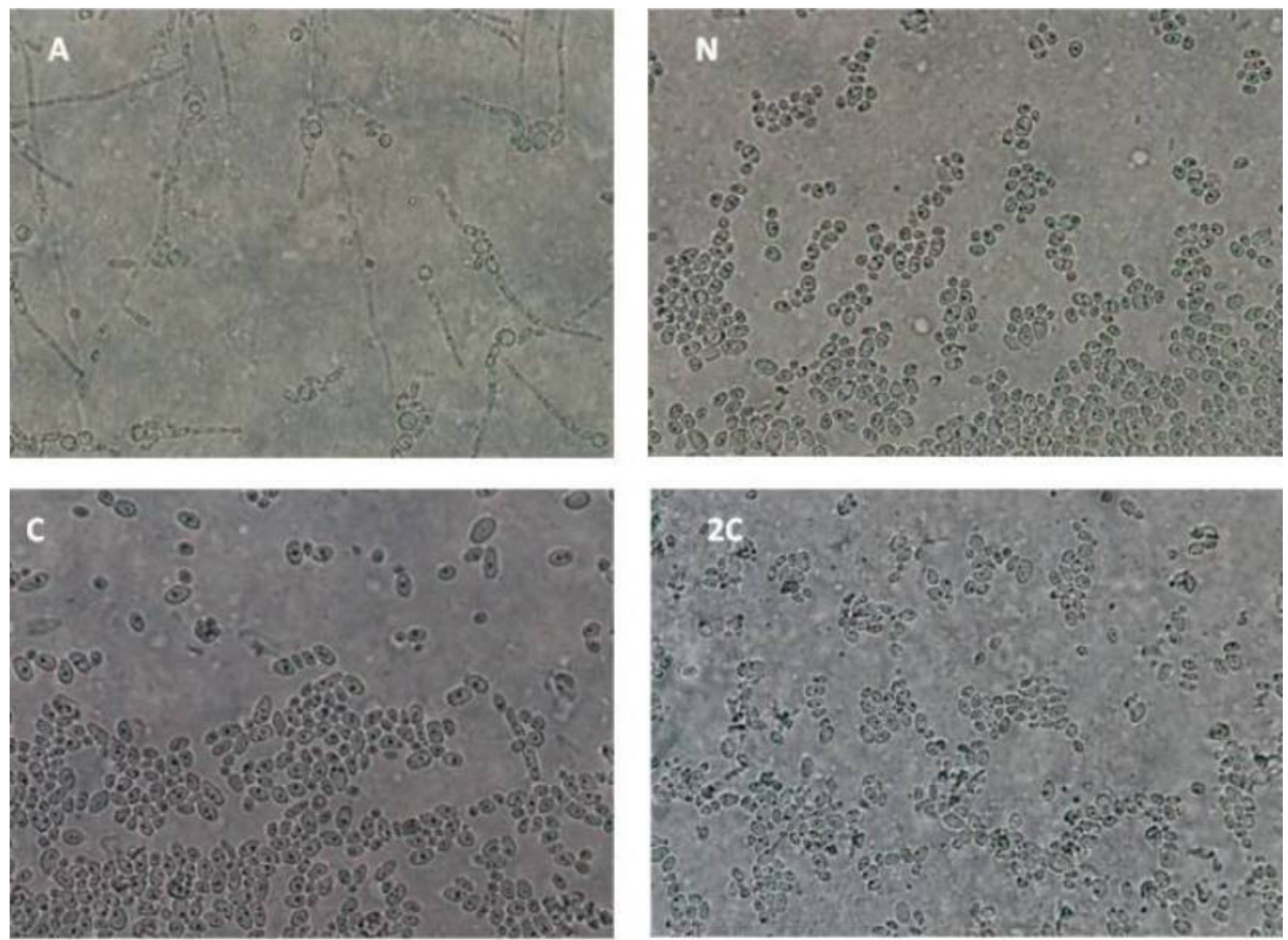

FIGURA 7. Micromorfologia de C. parapsilosis ATCC 90018.

A - Controle sem tratamento; $\mathrm{N}$ - Cultura tratada com nistatina (16 $\mu \mathrm{g} / \mathrm{mL}) ; \mathrm{C}$ - Cultura tratada com CIM do OEOg $(1,25 \mathrm{mg} / \mathrm{mL}) .2 \mathrm{C}$ Cultura tratada com $2 \times \mathrm{CIM}$ do OEOg $(2,5 \mathrm{mg} / \mathrm{mL})$. Aumento de $40 \mathrm{X}$.
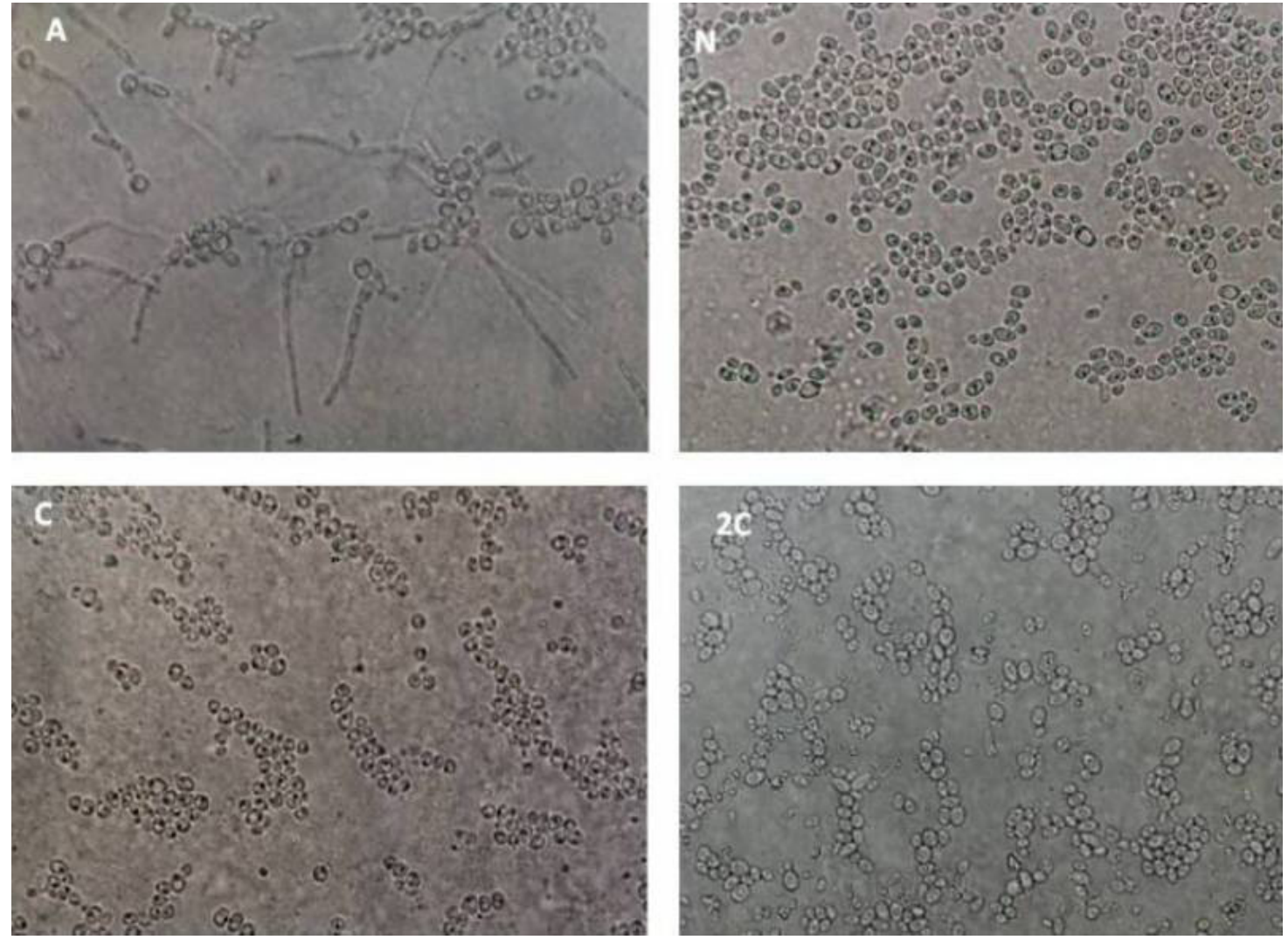

FIGURA 8. Micromorfologia de C. albicans ATCC 10231.

A - Controle sem tratamento; $N$ - Cultura tratada com nistatina $(16 \mu \mathrm{g} / \mathrm{mL}) ; \mathrm{C}$ - Cultura tratada com CIM do OEOg $(1,25 \mathrm{mg} / \mathrm{mL}) .2 \mathrm{C}-$ Cultura tratada com 2xCIM do OEOg $(2,5 \mathrm{mg} / \mathrm{mL})$. Aumento de $40 \mathrm{X}$. 


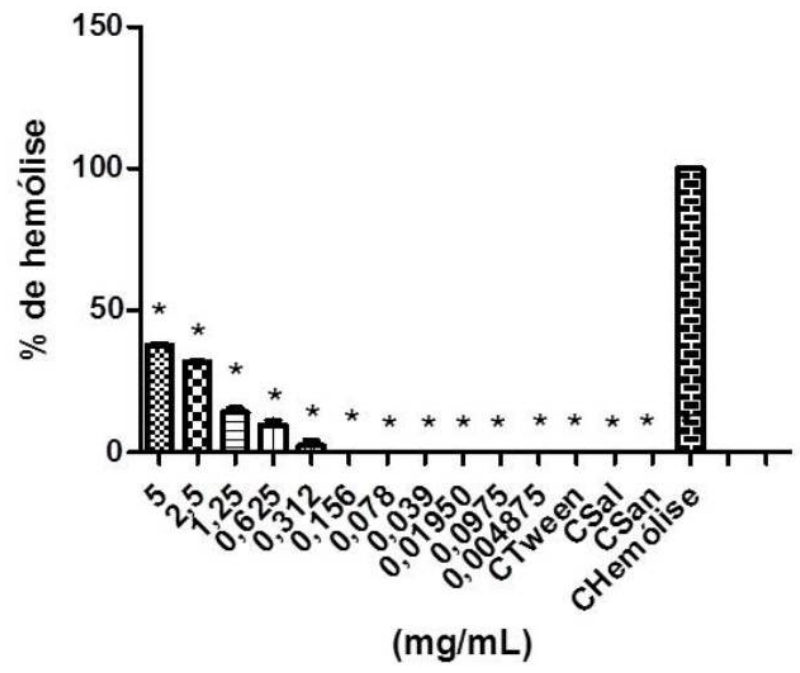

FIGURA 9. Atividade hemolítica do OEOg sobre hemácias humanas

Valores estão expressos pela média \pm EPM de três ensaios. A análise foi realizada por ANOVA, com pós-teste de Dunnet e valor de * $p<$ 0,05 quando comparado ao controle da hemólise (CHemólise).

na ação antimicrobiana dos componentes de óleos essenciais (Vieira et al., 2014). Para os compostos fenólicos timol, carvacrol e o eugenol, foram constatados os mais elevados potenciais antimicrobianos, o que pode ser explicado pela natureza ácida do grupo hidroxila, que forma uma ligação de hidrogenio com o centro ativo das enzimas dos micro-organismos, prevenindo a ação enzimática (Burt, 2004). Nesse contexto, podemos inferir que a ação antimicrobiana constatada para o OEOg, no presente estudo, seja atribuída em grande parte ao eugenol, seu componente majoritário. No entanto, por se tratar de uma mistura complexa de componentes, não podemos excluir a possibilidade de efeito sinérgico entre os demais componentes do OE, mesmo quando presentes em baixas concentrações.

No presente estudo, a atividade anticandida variou com a espécie de Candida e a concentração do OEOg. Os valores de CIM variaram de 0,625 a $1,25 \mathrm{mg} / \mathrm{mL}$, podendo ser classificadas como inbições moderadas (Duarte et al 2005) e estando de acordo com os resultados obtidos em estudo realizados por Nakamura et al. (2004).

A CIM do OEOg foi capaz de inibir o crescimento celular das cepas de Candida, quando comparada ao grupo sem tratamento, a partir de $4 \mathrm{~h}$ de contato, mantendo constante a contagem de celulas viáveis durante as 24 horas. No estudo do efeito do OEOg nas diferentes fases de crescimento (exponencial e estacionário), observou-se que as leveduras do gênero Candida estudadas são sensiveis ao OEOg nas duas fases de crescimento e que essa suscetibilidade é dependente da concentração. A influencia do metabolismo microbiano na ação do OEOg variou entre as cepas testadas, mas ficou evidente sua maior atividade inibitória nas primeiras 4 horas de contato com as leveduras, o que pode ser atribuido a possível corrência de decomposição do OE após esse tempo. A concentração de 2x CIM apresentou ação fungicida, sendo capaz de inviabilizar o cresimento de quase todas as cepas de Candida poucas horas após sua adição. Resultados semelhantes foram obtidos por Matasyoh et al. (2007).

O OEOg foi capaz de modular positivamente a atividade antifúngica do Cetoconazol sobre a cepa C. tropicalis ATCC 13803. A associação OEOg+CET potencializou a atividade antifúngica do OEOg e do CET, até quando usados nas concentrações de $1 / 16 \times$ CIM.

O OEOg promoveu um aumento na captação do cristal violeta indicando a ocorrência de alterações na permeabilidade da membrana celular, uma vez que o CV penetra pobremente na membrana externa íntegra, mas consegue fazê-lo facilmente quando a membrana está danificada. Devi et al. (2010), atestaram que o eugenol altera a permeabilidade da membrana, tornando-a mais permeáveis a alguns solutos, como o $\mathrm{CV}$.

Estudos anteriores demonstram que a alteração na permeabilidade da membrana celular é o mais provavel mecanismo de ação antimicrobiana dos OE (Burt, 2004), o que pode explicar a modulação positiva da associação OEOg+CET e o aumento da captação de CV, constatadas por nós.

A formação de hifas e pseudo-hifas, por representarem uma barreira à fagocitose e permitirem que a levedura fique aderida ao tecido epitelial, está relacionada com fatores de virulência expressos por Candida. Assim, alterações morfológicas podem ser associadas com a patogenicidade do micro-organismo (Romani et al., 2003). Os resultados do estudo mostram que o 
OEOg nas concentrações utilizadas (1x e 2x CIM) é capaz de reduzir o desenvolvimento de hifas, pseudo-hifas e clamidoconídios. Ao avaliarem a interferência de OE sobre a micromorfologia de fungos, Castro (2010) encontrou resultados que estão em concordância com os nossos.

Os resultados do nosso estudo mostram que CIM do OEOg para as cepas de Candida testadas apresentam uma baixa toxicidade, 14 e 10 $\%$, quando comparadas a anfotericina $B$ e fluconazol (Amber et al. 2010), o que sugere que o OEOg seja seguro para uso in vivo. É importante descatar o fato de que nas combinações OEOg+CET, capazes de modular positivamente a atividade do CET sobre $C$. tropicalis ATCC 13803, a CIM do OEOg é reduzida em até 16 vezes $(0,078 \mathrm{mg} / \mathrm{mL})$ e que nessa concentração a taxa de hemólise é de $0 \%$, tornando - OEOg um promissor candidato ao tratamento de infecções por esse levedura.

Nossos resultados destacam o OEOg como um candidato promissor ao desenvolvimento de um novo antifúngico de uso clínico, uma vez que o ele é capaz de reduzir a taxa de crescimento celular após $4 \mathrm{~h}$ de contato com as leveduras estudadas, além de apresentar capacidade de modular positivamente a ação do cetoconazol e possuir baixa toxicidade sobre hemácias humanas.

Embora o seu mecanismo de ação ainda não esteja totalmente esclarecido, os experimentos realizados permitem pressupor que o OEOg seja capaz de causar danos no envoltório celular e por consequência interferir no desenvolvimento de estruturas morfológicas ligadas à patogenicidade das leveduras. Deve-se ressaltar que, apesar de sua boa atividade antimicrobiana sobre Candida spp., ainda são necessários estudos adicionais para que o OEOg possa vir a se tornar um novo agente antifúngico.

Esse estudo é uma importante contribuição para o desenvolvimento de um novo antifúngico, por se tratar de uma ampla avaliação da ação antifúngica do OEOg, até então inexistente, sobre cepas de Candida por ser pioneiro em estudar seu efeito modulador sobre ATF de uso clínico, além de contribuir para o início da elucidação de seu mecanismo de ação sobre Candida spp..

\section{AGRADECIMENTO}

À Fundação Cearense de Apoio ao Desenvolvimento Científico e Tecnológico (Funcap).

\section{REFERÊNCAS}

AGUIAR, J.J.S. et al. Antibacterial and modifying-antibiotic activities of the essential oils of Ocimum gratissimum $\mathrm{L}$. and Plectranthus amboinicus L. European Journal of Integrative Medicine, v. 7, p. 151-156, 2015.

AHMAD, A. et al. Evolution of ergosterol biosynthesis inhibitors as fungicidal against Candida. Microbial Pathogenesis, v. 48, p. 35-41, 2010.

AHMAD, A. et al. Antifungal activity of Coriaria nepalensis essential oil by disrupting ergosterol biosynthesis and membrane integrity against Candida. Yeast, v. 28, p. 611-617, 2011.

AMBER, K. et al. Anticandidal effect of Ocimum sanctum essential oil and its synergy with fluconazole and ketoconazole. Phytomedicine, v. 17, p. 921-925, 2010.

BURT, S.A. Essential oils: their antibacterial properties and potential applications in foods - a review. International Journal of Food Microbiology, v. 94, p. 223-253, 2004.

CASTRO, R. D. Atividade antifúngica do óleo essencial de Cinnamomum zeylancum Blume (canela) e de sua associação com antifúngicos sintéticos sobre espécies de Candida. 2010. 170f. Tese (Doutorado Área de Concentração em Farmacologia) - Centro de Ciências da Saúde, Universidade Federal da Paraíba, João Pessoa-PB.

CECHINEL, V.F.; YUNES, R.A. Estratégias para a obtenção de compostos farmacologicamente ativos a partir de plantas medicinais. Conceitos sobre modificação estrutural para otimização da atividade. Química Nova, v. 21, n.1, p. 99-105, 1998.

CLSI - CLINICAL AND LABORATORY STANDARDS INSTITUTE. Método de referência para testes de diluição em caldo para a determinaçao da sensibilidade de leveduras à terapia antifúngica: Norma Aprovada. 2.ed. Norma M27-A2 do CLSI. Pennsylvania, 2008.51p.

COSTA, A.R.T. et al. Ação do óleo essencial de Syzygium aromaticum(L.) Merr. \& L.M.Perry sobre as hifas de alguns fungos fitopatogênicos. Revista brasileira de plantas medicinais, v.13, n.2, p. 240-245, 2011.

DAFERERA, D.J. et al. The effectiveness of plant essential oils on the growth of Botrytis cinerea, Fusarium sp. and Clavibacter michiganensis subsp.michiganensis. Crop Protection, v. 22, p. 39-443, 2003.

DEVI, K.P. et al. Eugenol (an essential oil of clove) acts as antibacterial agent against Salmonella typhi by disrupting the cellular membrane. Journal of Ethnopharmacology, v. 130, p. 107-115, 2010.

DUARTE, M.C. et al. Anti-Candida activity of brazilian medicinal plants. Journal of Ethnopharmacology, v. 97, p. 305-311, 2005.

EUCAST. Determination of minimum inhibitory concentrations (MICs) of antibacterial agents by broth dilution. Clinical Microbiology Journal, v. 9, n. 8, p. 1-7, 2003.

HARRIS, F.; PHOENIX, D.A. An investigation into the ability of C-terminal homologues of Escherichia coli low molecular mass penicillin-binding proteins 4,5 and 6 to undergo membrane interaction. Biochimie, v. 79, n. 4, p. 171-174, 1997.

MACIEL, M.A.M. et al. Plantas Medicinais: ANecessidade De Estudos Multidisciplinares. Química Nova, v. 25, n. 3, p. 429-438, 2002.

MATASYOH, L.G. et al. Chemical composition and antimicrobial activity of the essentialoil of Ocimum

Rev. Bras. PI. Med., Campinas, v.18, n.2, p.511-523, 2016. 
gratissimum L. growing in Eastern Kenya.African. Journal of Biotechnology, v. 6, n. 6, p. 760-765, 2007.

MATOS, F.J.A. Farmácias vivas: Sistema de utilização de plantas medicinais projetado para pequenas comunidades. 3.ed. Fortaleza. Edições UFC, 1998. 219p.

MATOS, F.J.A. Plantas Medicinais: Guia de seleção e emprego de plantas utilizadas em fitoterapia no nordeste do Brasil. 3.ed. Fortaleza: Edições UFC, 2007.425p.

MUROI, H.; KUBO, I. Antibacterial activity of anacardic acid and totarol, alone and in combination with methicillin, against methicillinresistant Staphylococcus aureus. Journal of Applied Bacteriology, v. 80, p. 387-39, 1996.

NAKAMURA, C.V. et al. In vitro activity os essential oil from Ocimum gratissimum L. against four Candida species. Research in Microbiology, v. 155, p. 579-586, 2004.

NOLDIN, V.F. Estudo fitoquímico das folhas e rizomas de Simaba ferruginea ST. HIL. e avaliação da atividade antiúlcera e antinociceptiva dos extratos e compostos isolados. 2005. 91f. Dissertação (Mestrado - Área de Concentração em Produtos Naturais) - Centro de Ciências da Saúde, Universidade do Vale do Itajaí, Santa Catarina.

PANDEY, A.K. et al. Chemistry and bioactivities of essential oils of some Ocimum species: an Overview. Asian Pacific Journal of Tropical Biomedicine, v. 4, n.9, p. 682-694,
2014.

REICHLING, J. et al. Essential Oils of Aromatic Plants with Antibacterial, Antifungal, Antiviral, and Cytotoxic Properties - an Overview. Forsch Komplementmed, v.16, p. 79-90, 2009.

ROMANI, L. et al. Adaptation of Candida albicans to the host environment: the role of morphogenesis in virulence and survival in mammalian hosts. Current Opinion in Microbiology, v. 6, n. 4, p. 338-343, 2003.

ROMEIRO, R. S. Métodos em Bacteriologia de plantas. 1.ed.Viçosa: Editora UFV, 2001. 279p.

SALES, G.W.P. Avaliação da atividade antimicrobiana e do mecanismo de ação do óleo essencial extraído da casca de frutos da Hymenaea courbail L. 2014. 141f. Dissertação (Mestrado - Área de Concentração em Biologia para Saúde) - Faculdade de Farmácia, Universidade Federal do Ceará, Fortaleza-CE.

SOUSA, M.P. et al. Constituintes químicos ativos e propriedades biológicas de plantas medicinais brasileiras. 2.ed. Fortaleza: Edições UFC, 2004. 445p.

VIEIRA, P.R.N. et al. Chemical composition and antifungal activity of essential oils from Ocimum species. Industrial Crops and Products, v. 55, p. 267-271, 2014.

ZUZARTE, M. et al. Antifungal activity of phenolicrich Lavandula multifida L. essential oil. European Journal of Clinical Microbiology \& Infectious Diseases, v. 31, p. 1359-1366, 2012. 